\title{
Comparison of once daily versus twice daily olmesartan in patients with chronic kidney disease
}

\author{
Yukinao Sakai \\ Anna Suzuki' \\ Koji Mugishima' \\ Yuichiro Sumi' \\ Yusuke Otsuka' \\ Tomoyuki Otsuka' \\ Dai Ohno' \\ Tsuneo Murasawa' \\ Shuichi Tsuruoka ${ }^{2}$ \\ 'Department of Nephrology, \\ Nippon Medical School Musashikosugi \\ Hospital, Kawasaki, Japan; ${ }^{2}$ Division \\ of Nephrology, Department of \\ Internal Medicine, Graduate School \\ of Medicine, Nippon Medical School, \\ Tokyo, Japan
}

This article was published in the following Dove Press journal: International Journal of Nephrology and Renovascular Disease 10 October 2013

Number of times this article has been viewed

Background: The effects of olmesartan (OLM) on blood pressure and kidney function in Japanese patients with chronic kidney disease (CKD) were compared between $20 \mathrm{mg}$ twice daily (BID) and $40 \mathrm{mg}$ once daily (QD) treatments.

Methods: The subjects were Japanese CKD patients with concurrent hypertension who had been treated with OLM $20 \mathrm{mg}$ BID for at least 3 months on an outpatient basis $(n=39)$. After a change in the treatment regimen to $40 \mathrm{mg}$ OLM QD (after breakfast), blood pressure (BP) $(n=39)$, morning home BP $(n=13)$, estimated glomerular filtration rate $(n=39)$, and urinary albumin-to-creatinine ratio $(\mathrm{n}=17)$ were monitored for 2 months.

Results: No significant change in office (mean \pm standard deviation [SD] [mmHg], $143.9 \pm 18.8 / 75.7 \pm 12.0$ to $141.6 \pm 16.1 / 74.7 \pm 11.7$, not significant [ns]) or early morning home (mean $\pm \mathrm{SD}[\mathrm{mmHg}], 133.8 \pm 15.9 / 71.2 \pm 11.5$ to $133.8 \pm 13.9 / 74.5 \pm 10.5$, ns) BP was observed 2 months after the change in dose. The estimated glomerular filtration rate increased significantly (mean $\pm \mathrm{SD}, 49.0 \pm 28.0$ to $51.8 \pm 27.0, P<0.05$ ), whereas urinary albumin-to-creatinine ratio did not change significantly (mean $\pm \mathrm{SD}, 0.551 \pm 0.445$ to $0.364 \pm 0.5194$, ns).

Conclusion: High-dose OLM administered BID and QD had similar effects on outpatient and early morning home BP in CKD patients, suggesting that the BID regimen can be safely changed to a QD regimen. For CKD patients with hypertension requiring continuous long-term treatment, the possibility that the QD regimen might bring a greater therapeutic effect was suggested. However, recognizing the best blood pressure control level for a CKD patient is still a matter of debate, and should ideally be personalized.

Keywords: high-dose angiotensin receptor blocker, hypertension, chronic kidney disease, compliance, olmesartan

\section{Introduction}

The renin-angiotensin-aldosterone system is activated in patients with chronic kidney disease (CKD), increasing the risk of cardiovascular events ${ }^{1}$ and accelerating the transition to end-stage renal failure, in addition to being closely associated with hypertension. ${ }^{2,3}$ Therefore, strict blood pressure (BP) control and treatment of underlying diseases is important.

However, strict BP control for 24 hours is challenging, even with once daily (QD) administration of an antihypertensive drug, and two divided doses are favorable in some cases. Because CKD is associated with decreased sodium excretion during the day and increased sodium excretion during the night in correlation with reduced kidney function, many patients have nondipper type hypertension in which nocturnal control of BP is frequently difficult. ${ }^{4}$ Therefore, to achieve a more stable efficacy of
Correspondence: Yukinao Sakai

Department of Nephrology, Nippon Medical School Musashikosugi Hospital, I-396 Kosugi-cho, Nakahara-ku, Kawasaki 2I I-8533, Japan

Tel +8I 447335 I 81 ext 2205

Fax $+8|447|$ II 8333

Email y-sakai@nms.ac.jp 
angiotensin receptor blockers (ARBs), many patients with CKD receive drugs twice daily (BID), in the morning and in the evening.

On the other hand, in patients with hypertension who require long-term continuous treatment, a smaller number of tablets and lower daily dosing frequency lead to good compliance, ${ }^{2}$ which improves the therapeutic efficacy and continuity of treatment. Therefore, drugs certain to control hypertension with a simple prescription are ideal.

In Japan, few studies have compared the effects of QD versus BID drug regimens on compliance, and no studies have compared the effects of QD versus BID olmesartan (OLM) administration.

OLM administered QD provides high continuity of treatment using ambulatory blood pressure monitoring (ABPM) or home blood pressure monitoring as compared with other ARBs,,$^{5-8}$ making the QD regimen the most promising.

In the present study, we examined the effects of QD (morning) versus BID (morning and evening) OLM treatment on office BP, morning home BP, and renal function in patients with $\mathrm{CKD}$ complicated by hypertension.

\section{Materials and methods Patients and protocol}

Thirty-nine consecutive Japanese outpatients (Tables 1 and 2) with CKD complicated by hypertension, treated with OLM $20 \mathrm{mg}$ BID (after breakfast and supper) for more than 3 months, were switched to OLM $40 \mathrm{mg}$ QD in the morning. Office BP and morning home BP were assessed, and renal function was examined by measuring serum creatinine levels to calculate estimated glomerular filtration rate (eGFR) and urinary albumin-to-creatinine ratio (UACR) to estimate proteinuria. The follow-up period for assessment of the stable antihypertensive efficacy of OLM was set at 2 months. ${ }^{9}$ Antihypertensive drugs were not added during the follow-up period. This work was purely an observational study, and written informed consent was obtained from all patients.

\section{Blood pressure measurement}

Office systolic and diastolic BP was measured every 4 weeks with the patient in a sitting position after 5 minutes of rest. Each BP measurement was determined using a sphygmomanometer, and the average of two measurements was calculated. Home BP was also calculated as the average of two measurements. We had instructed patients to maintain a home BP diary. Home BP was measured before the oral administration of OLM and within 1 hour after waking in
Table I Baseline characteristics of the study population $(n=39)$

\begin{tabular}{|c|c|}
\hline Parameter & $\begin{array}{l}\text { Twice daily dosing } \\
\text { n (\%) or mean } \pm \text { SD }\end{array}$ \\
\hline Number of patients & 39 \\
\hline Age (years) & $69.7 \pm 11.7$ \\
\hline Women & $16(42.1)$ \\
\hline \multicolumn{2}{|l|}{ Medical history } \\
\hline Chronic kidney disease & $39(100)$ \\
\hline Diabetic kidney & $18(46.1)$ \\
\hline Benign nephrosclerosis & II (28.2) \\
\hline IgA kidney & $4(10.2)$ \\
\hline Gouty kidney & $4(10.2)$ \\
\hline Nephropathy of pregnancy & $\mathrm{I}(2.5)$ \\
\hline Hepatorenal syndrome & I (2.5) \\
\hline eGFR $\left(\mathrm{mL} / \mathrm{min} / 1.73 \mathrm{~m}^{2}\right)$ & $49.0 \pm 28.3$ \\
\hline \multicolumn{2}{|l|}{ GI } \\
\hline$\geq 90$ & I (2.5) \\
\hline \multicolumn{2}{|l|}{$\mathrm{G} 2$} \\
\hline $60-89$ & $12(30.7)$ \\
\hline \multicolumn{2}{|l|}{ G3a } \\
\hline $45-59$ & $10(25.6)$ \\
\hline \multicolumn{2}{|l|}{ G3b } \\
\hline $30-44$ & $5(12.8)$ \\
\hline \multicolumn{2}{|l|}{ G4 } \\
\hline $15-29$ & $6(15.3)$ \\
\hline \multicolumn{2}{|l|}{ G5 } \\
\hline$<15$ & $5(12.8)$ \\
\hline
\end{tabular}

Abbreviations: eGFR, estimated glomerular filtration rate; G, stages of chronic kidney disease; IgA, immunoglobulin $\mathrm{A}$; $\mathrm{SD}$, standard deviation.

the morning. We followed the Japanese guidelines for the treatment of hypertension ${ }^{10}$ when assessing the patients' BP using the auscultation method and a mercury or automatic sphygmomanometer.

\section{Renal function}

Renal function was evaluated on the basis of the eGFR, which was calculated using an equation developed for the Japanese

Table 2 Antihypertensive treatment

\begin{tabular}{ll}
\hline & $\mathbf{n}(\%)$ \\
\hline $\begin{array}{l}\text { Olmesartan } \\
\text { Number of antihypertensive drugs }\end{array}$ & $39(100)$ \\
\hline & \\
2 & $9(23.0)$ \\
3 & $17(43.5)$ \\
$\geq 4$ & $8(20.5)$ \\
Drugs & $5(12.8)$ \\
Calcium channel blocker & \\
ACE inhibitor & $27(71)$ \\
Renin inhibitor & $8(21)$ \\
Aldosterone antagonist & $3(7.9)$ \\
Alpha blocker & $2(5.2)$ \\
Beta blocker & I $(2.6)$ \\
Diuretic & I $(2.6)$ \\
\hline
\end{tabular}

Abbreviation: ACE, angiotensin converting enzyme inhibitor. 
population, as recommended by the Japanese Society of Nephrology ${ }^{11}$ as,

$$
\begin{aligned}
\mathrm{eGFR}= & 194 \times \mathrm{sCrn}-1.094 \times \text { age }-0.287 \\
& (\times 0.739, \text { if female }),
\end{aligned}
$$

where $\mathrm{sCrn}$ is serum creatinine. The serum potassium concentration $(\mathrm{K})$ was measured. Urinary samples and blood samples were collected at approximately the same time. UACR was expressed as $\mathrm{g} / \mathrm{gCr}$.

\section{Statistical analysis}

The changes in BP were expressed as mean \pm standard deviation (SD) and analyzed using one-way analysis of variance. Serum creatinine and eGFR were expressed as mean \pm SD . The changes in serum creatinine and eGFR were analyzed using the paired $t$-test. UACR $(\mathrm{g} / \mathrm{gCr})$ was expressed as mean \pm standard error of the mean and analyzed using the paired $t$-test. All $P$-values $<0.05$ were considered statistically significant.

\section{Results}

\section{Patient characteristics}

Table 1 shows the background characteristics of the patients who received OLM $20 \mathrm{mg}$ BID. Table 2 shows the antihypertensive drug treatment regimens in these patients. A total of 39 patients with CKD complicated by hypertension, ranging in age from 41-90 years, were included in the study. Thirty patients used other antihypertensive drugs in addition to OLM.

\section{Blood pressure}

After 2 months of QD therapy, there was a small reduction in office BP, but the difference did not reach statistical significance. We had instructed all 39 patients to maintain a home BP diary, but only 13 of them adhered to this instruction during the follow-up period. Morning home BP did not differ significantly between QD and BID treatments (Figures 1 and 2; Table 3). Assessment of changes in BP up to 2 months after administration of OLM $40 \mathrm{mg}$ QD revealed no significant difference between the baseline value and that obtained at month 1 or 2. No significant change in BP from baseline to that at month 1 or 2 was detected in the 13 patients whose early morning home BP was measured.

\section{Renal function}

Table 4 shows the changes in eGFR, serum creatinine, $\mathrm{K}$, and UACR after 2 months of QD treatment.

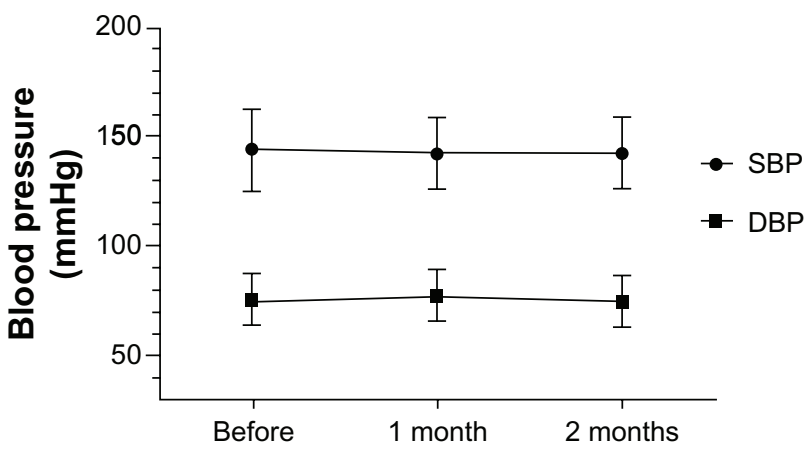

Figure I Changes in blood pressure during the course of treatment with high-dose olmesartan administered once daily.

Notes: One-way analysis of variance was used; results are expressed as mean \pm standard deviation.

Abbreviations: DBP, diastolic blood pressure; SBP, systolic blood pressure.

The eGFR significantly increased from the baseline value (Figure 3 and Table 4), whereas no significant change in creatinine or UACR was detected (Figure 4 and Table 4). These results indicated that the high-dose OLM BID regimen could be safely switched to the QD regimen in CKD patients with hypertension.

\section{Adverse reactions}

There was no withdrawal associated with hypotension or anemia while patients were on QD therapy, and no changes in laboratory values were observed. No significant change in $\mathrm{K}$ was detected (Table 4).

\section{Discussion}

In the present study, we showed that the high-dose OLM BID regimen could be safely switched to the QD regimen in CKD patients with hypertension. A high-dose BID regimen of ARBs is an effective approach for early-morning and evening control of BP and treatment-resistant hypertension in

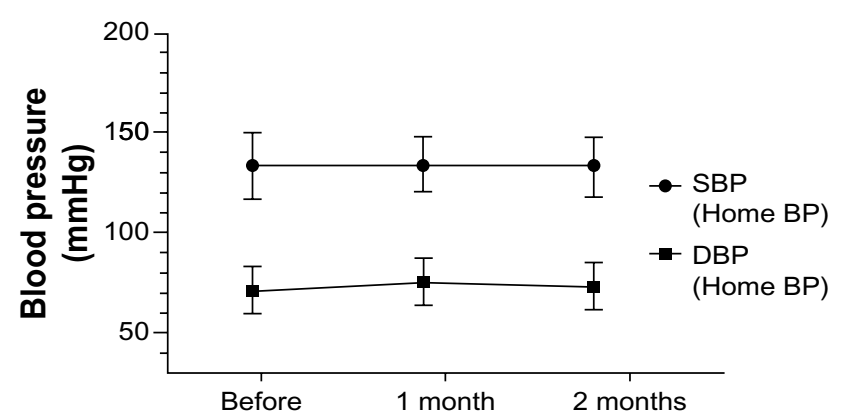

Figure 2 Changes of morning blood pressure during the course of treatment with high-dose olmesartan administered once daily.

Notes: One-way analysis of variance was used; results are expressed as mean \pm standard deviation.

Abbreviations: BP, blood pressure; DBP, diastolic blood pressure; SBP, systolic blood pressure. 
Table 3 Changes in office and home systolic/diastolic blood pressure (SBP/DBP) from baseline to after $I$ and 2 months of once daily high-dose olmesartan treatment

\begin{tabular}{lllll}
\hline Parameter & Baseline & I month & 2 months & P-value \\
\hline $\begin{array}{l}\text { Office SBP } \\
(n=39)\end{array}$ & $143.9 \pm 18.8$ & $142.0 \pm 16.3$ & $141.6 \pm 16.1$ & 0.826 \\
$\begin{array}{l}\text { Office DBP } \\
(n=39)\end{array}$ & $75.7 \pm 12.0$ & $77.3 \pm 12.7$ & $74.7 \pm 11.7$ & 0.650 \\
$\begin{array}{l}\text { Home SBP } \\
(n=13)\end{array}$ & $133.8 \pm 15.9$ & $134.0 \pm 13.5$ & $133.8 \pm 13.9$ & 0.999 \\
$\begin{array}{l}\text { Home DBP } \\
(n=13)\end{array}$ & $71.2 \pm 11.5$ & $75.6 \pm 12.1$ & $74.5 \pm 10.5$ & 0.621 \\
\hline
\end{tabular}

Notes: One-way analysis of variance was used; results are expressed as mean \pm standard deviation. Measurements $\mathrm{mmHg}$.

CKD patients with increased renin-angiotensin-aldosterone system activity.

Nonetheless, a reduction in the number of daily tablets and the dosing frequency may improve treatment compliance ${ }^{12-14}$ in CKD patients with hypertension requiring long-term continuous therapy, potentially improving the therapeutic effect in these patients.

On the basis of the meta analysis ${ }^{15}$ that revealed a difference in treatment compliance between QD and BID regimens and reports that treatment compliance can be improved by the measurement of home $\mathrm{BP},{ }^{16}$ it is plausible that switching to the QD regimen resulted in improved treatment compliance during the follow-up period. Although a home BP diary was maintained by $33 \%$ of the patients in this study, all patients were told of the importance of home BP measurements and instructed on how to measure home BP. Although there was no significant difference between regimens, a slight decrease in office BP was detected after switching to the QD regimen, indicating the possibility that the QD regimen might have contributed to decreased

Table 4 Renal function and potassium during once daily highdose olmesartan treatment for 2 months

\begin{tabular}{|c|c|c|c|}
\hline Parameter & $\begin{array}{l}\text { Baseline } \\
\text { Mean } \pm \text { SD }\end{array}$ & $\begin{array}{l}2 \text { months } \\
\text { Mean } \pm \text { SD }\end{array}$ & $p$-value \\
\hline $\begin{array}{l}\text { eGFR } \mathrm{mL} / \mathrm{min} / \mathrm{l} .73 \mathrm{~m}^{2} \\
(\mathrm{n}=39)\end{array}$ & $49.0 \pm 28.0$ & $51.8 \pm 27.0 *$ & 0.0424 \\
\hline $\begin{array}{l}\text { Creatinine } \mathrm{mg} / \mathrm{dL} \\
(\mathrm{n}=39)\end{array}$ & $\mathrm{I} .53 \pm \mathrm{I} .48$ & $1.48 \pm 1.38$ & 0.279 \\
\hline $\begin{array}{l}\mathrm{K} \mathrm{mEq} / \mathrm{L} \\
(\mathrm{n}=39)\end{array}$ & $4.48 \pm 0.47$ & $4.42 \pm 0.46$ & 0.686 \\
\hline Parameter & $\begin{array}{l}\text { Baseline } \\
\text { Mean } \pm \text { SD }\end{array}$ & $\begin{array}{l}2 \text { month } \\
\text { Mean } \pm \text { SD }\end{array}$ & $p$-value \\
\hline $\begin{array}{l}\text { UACR } g / g C r \\
(n=17)\end{array}$ & $0.551 \pm 0.445$ & $0.364 \pm 0.5194$ & 0.119 \\
\hline
\end{tabular}

Note: ${ }^{*} P<0.05$ paired $t$-test.

Abbreviations: eGFR, estimated glomerular filtration rate; SD, standard deviation; UACR, urinary albumin-to-creatinine ratio.

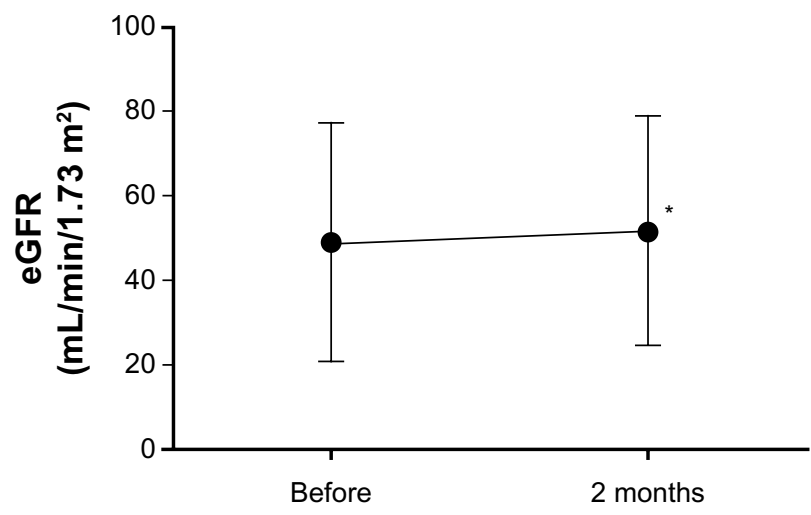

Figure 3 Changes of eGFR during administration of once daily high-dose of olmesartan.

Notes: Results are expressed as mean \pm standard deviation; paired $t$-test. Abbreviation: eGFR, estimated glomerular filtration rate. $* P<0.05$.

intraglomerular pressure and UACR (without any significant difference), and that increased GFR cannot be ruled out.

It is generally accepted that the inhibitory effect on proteinuria can be explained by the effects of ARB on decreasing intraglomerular pressure and reducing glomerular afterload. Although the results of this study did not show any significant difference, a slight decrease in office BP was detected, as is the case in decreased UACR. Undeniably, this decrease in office BP induced the decrease in UACR.

The superior continuous blood pressure-lowering effect of OLM compared with other drugs has recently been reported, ${ }^{5-8}$ and the Japanese ABPM guidelines state that a sustained effect of OLM can be anticipated. In addition, a US study comparing the sustained effect of OLM administered BID using ABPM in outpatients with moderate to severe essential hypertension showed no significant difference in mean systolic or diastolic blood pressure during the final hour. ${ }^{14}$ Our study showed that the blood pressure-lowering

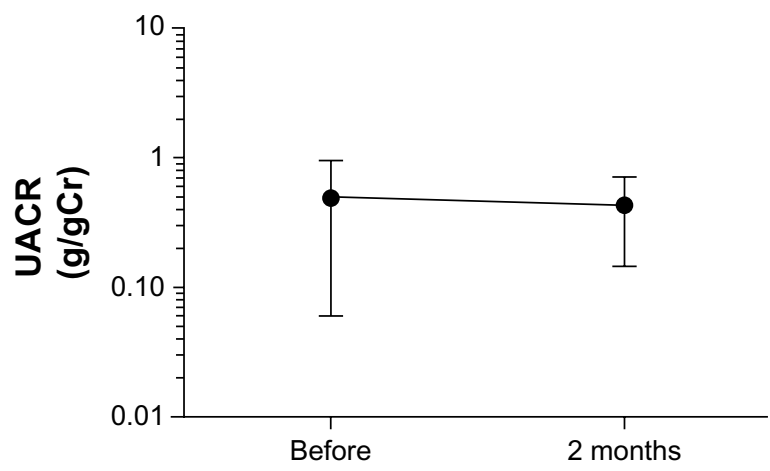

Figure 4 Changes of UACR during administration of once daily high-dose of olmesartan.

Notes: Results are expressed as mean \pm standard deviation; paired $t$-test. Abbreviation: UACR, urinary albumin-to-creatinine ratio. 
and sustained effects of high-dose OLM administered QD and BID were similar. OLM administered in $40 \mathrm{mg}$ tablets QD reduces the number of tablets prescribed to CKD patients and could therefore be expected to improve treatment compliance. Furthermore, we showed increased eGFR after 2 months of treatment. However, further examination is necessary to ascertain whether this improvement is attributable to mild decreases in blood pressure or whether it is associated with improved compliance.

\section{Conclusion}

OLM administered QD has a sustained effect and can control early morning blood pressure in CKD patients with hypertension. In addition, its effects are not likely to be influenced by clinical conditions or meals. Therefore, treatment with OLM can be adjusted to the lifestyles of patients to improve treatment compliance and enhance the antihypertensive effect in CKD patients with hypertension requiring long-term therapy. Recognizing the best blood pressure control level for a CKD patient is still a matter of debate and should ideally be personalized.

\section{Disclosure}

The authors report no conflicts of interest in this work.

\section{References}

1. Go AS, Chertow GM, Fan D, McCulloch CE, Hsu CY. Chronic kidney disease and the risks of death, cardiovascular events, and hospitalization. N Engl J Med. 2004;351(13):1296-1305.

2. Sleight P, Redon J, Verdecchia P, et al; ONTARGET investigators. Prognostic value of blood pressure in patients with high vascular risk in the Ongoing Telmisartan Alone and in combination with Ramipril Global Endpoint Trial study. J Hypertens. 2009;27(7): 1360-1369.

3. Ogihara T, Saruta T, Rakugi H, et al; CASE-J trial Group. Relationship between the achieved blood pressure and the incidence of cardiovascular events in Japanese hypertensive patients with complications: a subanalysis of the CASE-J trial. Hypertens Res. 2009;32(4):248-254.
4. Fukuda M, Munemura M, Usami T, et al. Nocturnal blood pressure is elevated with natriuresis and proteinuria as renal function deteriorates in nephropathy. Kidney Int. 2004;65(2):621-625.

5. Nakayama S, Watada H, Mita T, et al. Comparison of effects of olmesartan and telmisartan on blood pressure and metabolic parameters in Japanese early-stage type-2 diabetics with hypertension. Hypertens Res. 2008;31(1):7-13.

6. Brunner HR, Arakawa K. Antihypertensive efficacy of olmesartan medoxomil and candesartan cilexetil in achieving 24-hour blood pressure reductions and ambulatory blood pressure goals. Clin Drug Investig. 2006;26(4):185-193.

7. Smith DH, Dubiel R, Jones M. Use of 24-hour ambulatory blood pressure monitoring to assess antihypertensive efficacy: a comparison of olmesartan medoxomil, losartan potassium, valsartan, and irbesartan. Am J Cardiovasc Drugs. 2005;5(1):41-50.

8. Miyakawa M. Comparative efficacy of angiotensin II receptor blockers on early morning blood pressure in patients with essential hypertension: final report. Japanese. Therapeutic Research. 2009;30:1879-1882.

9. Mitsuyoshi N, Takanori T, Atsumi O, Shigeto K. Investigation of relationship between pharmacokinetics and antihypertensive effect of CS-866 (olmesartan medoxomil) in mild to moderate essential hypertensive patients. J Clin Ther Med. 2003;19(12):1397-1420.

10. Ogihara T, Kikuchi K, Matsuoka H, et al; Japanese Society of Hypertension Committee. The Japanese Society of Hypertension Guidelines for the Management of Hypertension (JSH 2009). Hypertens Res. 2009;32(1):3-107.

11. Matsuo S, Imai E, Horio M, et al; Collaborators developing the Japanese equation for estimated GFR. Revised equations for estimated GFR from serum creatinine in Japan. Am J Kidney Dis. 2009;53(6):982-992.

12. Schroeder K, Fahey T, Ebrahim S. How can we improve adherence to blood pressure-lowering medication in ambulatory care? Systematic review of randomized controlled trials. Arch Intern Med. 2004; 164(7):722-732.

13. Mazzaglia G, Ambrosioni E, Alacqua M, et al. Adherence to antihypertensive medications and cardiovascular morbidity among newly diagnosed hypertensive patients. Circulation. 2009;120(16):1598-1605.

14. Matsumura K, Arima H, Tominaga M, et al; COMFORT Investigators. Does a combination pill of antihypertensive drugs improve medication adherence in Japanese? A randomized controlled trial. Circ J. 2012;76(6): 1415-1422.

15. Iskedjian M, Einarson TR, MacKeigan LD, et al. Relationship between daily dose frequency and adherence to antihypertensive pharmacotherapy: evidence from a meta-analysis. Clin Ther. 2002;24(2): 302-316.

16. Ashida T, Sugiyama T, Okuno S, Ebihara A, Fujii J. Relationship between home blood pressure measurement and medication compliance and name recognition of antihypertensive drugs. Hypertens Res. 2000;23(1):21-24.

\section{Publish your work in this journal}

The International Journal of Nephrology and Renovascular Disease is an international, peer-reviewed open-access journal focusing on the pathophysiology of the kidney and vascular supply. Epidemiology, screening, diagnosis, and treatment interventions are covered as well as basic science, biochemical and immunological studies. The journal welcomes original research, clinical studies, reviews \& evaluations, expert opinion and commentary, case reports and extended reports. The manuscript management system is completely online and includes a very quick and fair peerreview system, which is all easy to use. Visit http://www.dovepress.com/ testimonials.php to read real quotes from published authors. 